\title{
EFEKTIVITAS LAYANAN INFORMASI DENGAN PENDEKATAN CONTEXTUAL TEACHING AND LEARNING UNTUK MENINGKATKAN KEPERCAYAAN DIRI SISWA DALAM BELAJAR
}

\author{
Siska Mardes ${ }^{1}$, Firman $^{2}$, Riska Ahmad $^{3}$
}

Email : firman@konselor.org

\begin{abstract}
The confidence of students in learning can be seen from the students 'daily learning activities, namely fear for suggested, ignore his social life, often looked glum in learning, afraid to form your own opinion, and many students are not responsible for the given task master, so many students who cheated. One of the efforts made to improve the confidence of students in learning is by information services. This research aims to test the effectiveness of information services by using contextual teaching and learning approaches to increase the confidence of students in learning. This research using quantitative methods. This type of research is Quasi Experiment with PretestPosttest design Control Group Design. The population of this research was the students at SMP Pembangunan Laboratorium UNP Padang and The sample was chosen by using Purposive Sampling Technique. Research instrument used with Likert scale model, then analyzed using the Wilcoxon Signed Ranks Test and Kolmogorov-Smirnov Two Sample Independent with the help of SPSS version 17.00. In general the findings of this research it can be concluded that the information services with the contextual approach to teaching and learning can improve the confidence of students in learning.
\end{abstract}

\section{Keywords: The Confidence Of Students In Learning, Information Services}

\section{PENDAHULUAN}

Pendidikan merupakan upaya dasar untuk potensi diri sebagaimana difitrahkan oleh Sang Maha Pencipta, diselenggarakan dari diri individu, untuk individu, dan oleh individu itu sendiri. Dalam hal ini, perbincangan tentang pendidikan, tidak lain adalah manusia, dengan kata lain perbincangan tentang pendidikan yang secara keilmuan mengarah kepada ilmu pendidikan, berpusat pada individu dengan segenap seluk-beluknya, dari awal kesejatian individu sampai dengan kenyataan kehidupan sehari-hari, dan sampai akhir hayat. Hal ini didasarkan dan sepenuhnya mengacu kepada pengertian pendidikan sebagaimana tertuang dalam Undang-undang No. 20 tahun 2003 tentang Sistem Pendidikan Nasional, Pasal 1 Butir 1.
Surya (2007:3) menjelaskan bahwa munculnya gejala tidak percaya diri pada anak ketika hendak melakukan sesuatu terkait erat dengan persepsi diri anak terhadap konsep dirinya sendiri, tidak percaya diri berarti ungkapan pernyataan ketidakmampuan anak untuk melaksanakan atau mengerjakan sesuatu, anak berpikir dan menilai negatif dirinya sehingga timbul perasaan tidak menyenangkan dan kecenderungan untuk segera menghindari atas apa yang hendak dilakukannya. Rakhmat (2010:109) mengemukakan bahwa kepercayaan diri dapat diartikan sebagai suatu kepercayaan terhadap diri sendiri yang dimiliki oleh setiap individu dalam kehidupannya serta bagaimana orang tersebut memandang dirinya secara utuh dengan mengacu pada konsep diri.

\footnotetext{
${ }^{1}$ Siska Mardes, Mahasiswa Program Studi S2 Bimbingan dan Konseling, Fakultas Ilmu Pendidikan, Universitas Negeri Padang

${ }^{2}$ Firman, Pembimbing 1, Dosen Program Studi S2 Bimbingan dan Konseling, Fakultas Ilmu Pendidikan, Universitas Negeri Padang

${ }^{3}$ Riska Ahmad, Pembimbing 2, Dosen Program Studi S2 Bimbingan dan Konseling, Fakultas Ilmu Pendidikan, Universitas Negeri Padang
} 
Proses terbentuknya rasa percaya diri menurut Hakim (2002:6) secara garis besar berasal dari terbentuknya kepribadian yang baik sesuai dengan proses perkembangan yang melahirkan kelebihan-kelebihan tertentu. Pemahaman seseorang terhadap kelebihan-kelebihan yang dimilikinya akan melahirkan keyakinan yang kuat untuk bisa berbuat segala sesuatu dengan memanfaatkan kelebihan itu, sebaliknya pemahaman dan reaksi positif seorang terhadap kelemahankelemahan yang menimbulkan rasa rendah diri atau sulit menyesuaikan diri, dan pengalaman di dalam menjalani berbagai aspek kehidupan dengan menggunakan segala kelebihan yang ada pada dirinya.

Hasil wawancara dengan guru BK/Konselor serta beberapa orang guru mata pelajaran di SMP Pembangunan Laboratorium UNP Padang pada tanggal 19 Januari 2015 terlihat masih banyak siswa yang takut dalam mengemukakan pendapat, takut bertanya, tidak percaya terhadap kemampuan yang dimilikinya sehingga menyebabkan siswa banyak menyontek, berdiam diri dan tidak semangat dalam mengikuti pelajaran.

Walgito (2004:10) menjelaskan bahwa bimbingan dan konseling merupakan kegiatan bersumber pada kehidupan manusia. Adapun yang dimaksud dengan layanan informasi menurut Prayitno (2013:9) adalah layanan bimbingan konseling yang membantu peserta didik menerima dan memahami berbagai informasi diri, sosial, belajar, karir/jabatan, dan pendidikan lanjutan secara terarah, objektif dan bijak. Selanjutnya, Ahmad (2013:77) menjelaskan bahwa informasi dibutuhkan dan diperlukan dalam semua aspek kehidupan manusia. Seseorang boleh jadi mengalami masalah karena kekurangan, ketiadaan dan kesalahan informasi. Layanan informasi adalah layanan yang membantu peserta didik menerima, memahami berbagai informasi diri, sosial, belajar, karier, jabatan, dan pendidikan lanjutan.

Pelaksanaan layanan informasi telah dilakukan oleh guru BK/Konselor, akan tetapi layanan informasi yang dilaksanakan belum optimal. Idealnya dalam pelaksanaan layanan informasi dapat menggunakan berbagai pendekatan agar siswa tidak bosan atau jenuh mengikuti kegiatan pembelajaran di kelas. Salah satu pendekatan yang dapat digunakan pada layanan informasi adalah dengan menggunakan pendekatan contextual teaching and learning.

Daryanto dan Rahardjo (2012:156) menjelaskan bahwa, "Pendekatan Contextual teaching and learning adalah suatu proses pendidikan yang holistik dan bertujuan memotivasi siswa untuk memahami makna materi pelajaran yang dipelajarinya dengan mengkaitkan materi tersebut dengan konteks kehidupan mereka sehari-hari (konteks pribadi, sosial, dan kultural) sehingga siswa memiliki pengetahuan/keterampilan yang secara fleksibel dapat diterapkan (ditransfer) dari satu permasalahan/konteks ke permasalahan/konteks lainnya".

Berdasarkan uraian di atas pendekatan contextual teaching and learning yang digunakan diharapkan dapat meningkatkan kepercayaan diri siswa dalam belajar, agar siswa mampu mengemukakan pendapatnya di dalam belajar serta keyakinan siswa dalam mengerjakan tugas tanpa menyontek. Pendekatan contextual teaching and learning diduga dapat meningkatkan kepercayaan diri siswa dalam belajar yaitu dengan memberikan berbagai materi yang sesuai dengan keadaan siswa, khususnya siswa yang takut untuk mengemukakan pendapatnya di dalam belajar, sehingga dengan pendekatan contextual teaching and learning siswa mampu untuk mengemukakan pendapatnya di dalam belajar.

Penelitian ini secara umum bertujuan untuk menguji efektivitas layanan informasi dengan pendekatan contextual teaching and learning untuk meningkatkan kepercayaan diri siswa dalam belajar. Sedangkan tujuan khusus untuk menguji: (1) perbedaan kepercayaan diri siswa dalam belajar pada kelompok eksperimen sebelum dan sesudah diberikan layanan informasi dengan pendekatan contextual teaching and learning, 
perbedaan kepercayaan diri siswa dalam belajar pada kelompok kontrol sebelum dan sesudah diberikan layanan informasi tanpa pendekatan contextual teaching and learning, (3) perbedaan kepercayaan diri siswa dalam belajar pada kelompok eksperimen yang diberikan layanan informasi dengan pendekatan contextual teaching and learning, dengan siswa pada kelompok kontrol yang diberikan layanan informasi tanpa pendekatan contextual teaching and learning.

\section{METODOLOGI PENELITIAN}

Penelitian ini menggunakan metode kuantitatif. Jenis penelitian ini adalah Quasi Experiment dengan rancangan Pretest-Posttest Control Group Design. Populasi penelitian adalah siswa SMP Pembangunan Laboratorium UNP Padang dan sampel dipilih menggunakan teknik Purposive Sampling. Instrumen penelitian yang digunakan adalah angket dengan model Skala Likert. Uji validitas instrumen penelitian melalui uji validitas isi oleh tiga orang ahli dan juga dilakukan menggunakan Spearman Rank Correlation dan uji reliabilitas menggunakan rumus Alpha Cronbach. Selanjutnya, data yang diperoleh dianalisis dengan menggunakan uji Wilcoxon Signed Ranks Test dan Kolmogorov-Smirnov 2 Independent Samples dengan bantuan SPSS versi 17.00.

\section{HASIL DAN PEMBAHASAN}

\section{Hasil}

\section{a. Perbedaan Kepercayaan Diri Siswa dalam Belajar pada Kelompok Eksperimen \\ Data penelitian yang diperoleh pada kelompok eksperimen sebelum dan sesudah diberikan perlakuan dapat dilihat pada gambar berikut.}

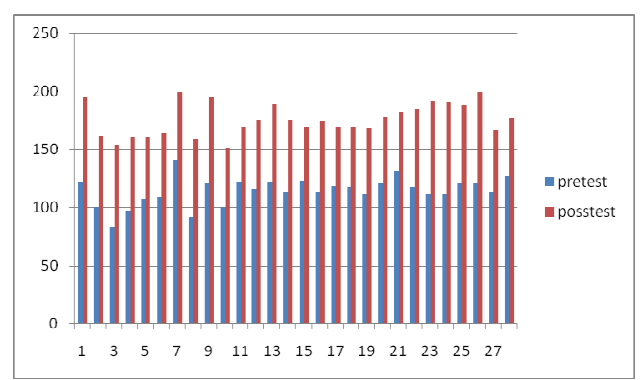

Gambar 1. Hasil Pretest dan Posttest Kepercayaan Diri Siswa dalam Belajar Kelompok Eksperimen

Berdasarkan Gambar 1 dapat diketahui bahwa terdapat perbedaan tingkat kepercayaan diri siswa dalam belajar sebelum dan sesudah diberi perlakuan layanan informasi dengan menggunakan pendekatan contextual teaching and learning. Dari 28 orang siswa yang mendapat perlakuan, semua siswa mengalami peningkatan.

b. Perbedaan Kepercayaan Diri Siswa dalam Belajar pada Kelompok Kontrol

Data penelitian yang diperoleh pada kelompok kontrol sebelum dan sesudah diberikan perlakuan dapat dilihat pada gambar berikut.

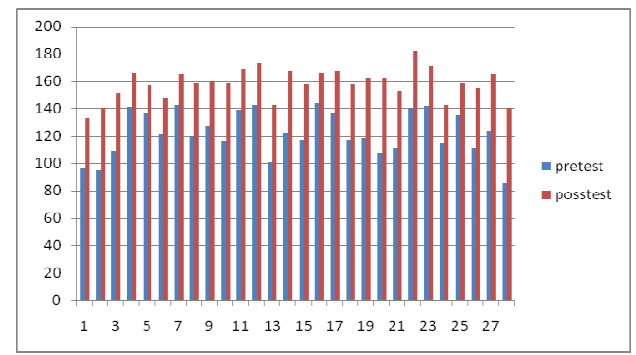

Gambar 2. Hasil Pretest dan Posttest Kepercayaan Diri Siswa dalam Belajar Kelompok Kontrol

Berdasarkan Gambar 2 diketahui bahwa terdapat perubahan antara pretest dan posttest yang diberikan perlakuan layanan informasi tanpa menggunakan pendekatan contextual teaching and learning. Dari 28 orang siswa semuanya mengalami perubahan, sehingga berada pada kategori tinggi dan sedang.

c. Perbedaan Kepercayaan Diri Siswa dalam Belajar pada Kelompok Eksperimen dan pada Kelompok Kontrol

Data penelitian yang diperoleh pada kelompok eksperimen dan kelompok kontrol sesudah diberikan perlakuan terdapat pada gambar berikut. 


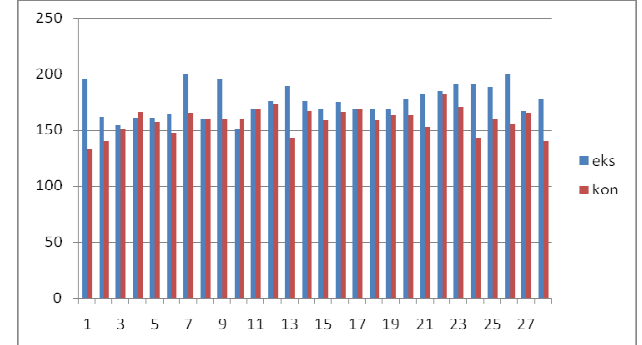

Gambar 3. Perbedaan Posttest Kelompok Eksperimen dan Kelompok Kontrol

Berdasarkan gambar di atas, terlihat bahwa kepercayaan diri siswa dalam belajar kelompok eksperimen yang diberikan layanan informasi dengan pendekatan contextual teaching and learning dan kelompok kontrol yang diberikan layanan informasi tanpa pendekatan contextual teaching and learning terdapat perbedaan.

\section{Pembahasan}

a. Perbedaan Kepercayaan Diri Siswa dalam Belajar Kelompok Eksperimen (Pretest dan Posttest)

Hipotesis pertama yang diuji dalam penelitian ini dapat diterima, yaitu "Terdapat perbedaan kepercayaan diri siswa dalam belajar kelompok eksperimen sebelum dan sesudah diberikan layanan informasi dengan pendekatan contextual teaching and learning”.

Proses kegiatan layanan informasi dengan pendekatan contextual teaching and learning, siswa menjadi sangat antusias dan aktif mengikuti diskusi sehingga kegiatan layanan ini banyak memperoleh hal yang baru yang dapat dimanfaatkan dalam kehidupan belajarnya. Oleh karena itu, pemberian layanan informasi yang tepat dan berarti bagi siswa akan memberikan pemahaman dan pengetahuan kepada siswa berkaitan dengan kepercayaan diri siswa dalam belajar.

Berdasarkan penjelasan di atas dapat dipahami bahwa kiranya perlu adanya suatu upaya untuk melaksanakan layanan informasi dengan pendekatan contextual teaching and learning khusus materi kepercayaan diri siswa dalam belajar, sehingga siswa tidak hanya mendapatkan pengetahuan dan wawasan secara umum. Hal yang terlihat selama proses pengamatan yang dilakukan ketika siswa mengikuti layanan informasi adalah siswa antusias dan mulai berani mengeluarkan pendapat, siswa mampu menghargai orang lain yang sedang berbicara, serta siswa mulai memiliki ketertarikan untuk mengetahui informasi tentang kepercayaan diri dan manfaatnya.

Sebagaimana yang dinyatakan Fatimah (2006:149) karakteristik individu yang mempunyai rasa percaya diri yang proposional, diantaranya adalah adalah; percaya akan kompetensi/kemampuan diri hingga tidak membutuhkan pujian, pengakuan, penerimaan, atau pun rasa hormat orang lain, tidak terdorong untuk menunjukkan sikap konformis demi diterima oleh orang lain atau kelompok, berani menerima dan menghadapi penolakkan orang lain, berani menjadi diri sendiri, punya pengendalian diri yang baik (tidak moody dan emosinya stabil), memiliki internal locus of control (memandang keberhasilan atau kegagalan, tergantung dari usaha diri sendiri dan tidak mudah menyerah pada nasib atau keadaan serta tidak tergantung/mengharapkan bantuan orang lain), mempunyai cara pandang yang positif terhadap diri sendiri, orang lain dan situasi di luar dirinya, memiliki harapan yang realistik terhadap diri sendiri, sehingga ketika harapan itu tidak terwujud, seseorang tetap mampu melihat sisi positif dirinya dan situasi yang terjadi. 


\section{b. Perbedaan Kepercayaan Diri Siswa dalam Belajar Kelompok Kontrol (Pretest dan Posttest)}

Hipotesis kedua yang diuji dalam penelitian ini dapat diterima, yaitu terdapat perbedaan kepercayaan diri siswa dalam belajar kelompok kontrol sebelum dan sesudah diberikan layanan informasi tanpa pendekatan contextual teaching and learning.

Hasil penelitian menunjukkan bahwa, perbedaan perolehan skor kepercayaan diri siswa dalam belajar pada pretest dan posttest pada kelompok kontrol tidak terlalu besar.

Penerapan layanan informasi tanpa pendekatan contextual teaching and learning kepada siswa di kelompok kontrol, membuat daya penggerak yang ada pada siswa tidak bekerja secara maksimal. Hal ini dapat diketahui dari pengamatan yang terlihat siswa hanya diam dan mendengarkan apa yang dijelaskan, siswa tidak antusias dalam layanan yang diberikan. Hal tersebut disebabkan karena layanan informasi tanpa pendekatan contextual teaching and learning hanya memberikan pengetahuanpengetahuan, namun kurang terjadi keaktifan dan interaksi yang efektif. Menurut Prayitno (2004:259) layanan informasi adalah layanan yang diberikan dengan tujuan untuk memberikan pemahaman kepada individu yang berkepentingan tentang berbagai hal yang diperlukan untuk menjalani suatu tugas yang diperlukan dalam mencapai tujuan yang telah direncanakan.

c. Perbedaan Kepercayaan Diri Siswa dalam Belajar Kelompok Eksperimen dan Kelompok Kontrol

perbedaan antara keduanya walaupun tidak begitu signifikan, yang mana layanan informasi dengan menggunakan pendekatan contextual teaching and learning lebih efektif daripada layanan informasi secara konvensional.

Sehubungan dengan adanya layanan informasi ini, para siswa diharapkan dapat memiliki pengetahuan dan wawasan mengenai hidupnya dimasa yang akan datang. Menurut Prayitno (2012:49) informasi sangat diperlukan bagi setiap individu untuk kepentingan hidup dan perkembangannya. Informasi yang diperoleh siswa bertujuan untuk memahami sesuatu hal yang berhubungan dengan seluk beluk kehidupan yang disesuaikan dengan informasi apa yang dibutuhkan pada masa remaja. Apabila tidak memperoleh informasi yang benar atau luas, maka dalam belajar di sekolah, individu diperkirakan akan menghadapi masalah dan kesulitan, baik di lingkungan sekolah, keluarga, dan masyarakat.

\section{KESIMPULAN}

Berdasarkan hasil penelitian yang diperoleh, dan setelah melakukan analisis statistik serta uji hipotesis, maka dapat disimpulkan secara umum bahwa layanan informasi dengan pendekatan contextual teaching and learning dapat meningkatkan kepercayaan diri siswa dalam belajar, secara khusus temuan penelitian ini sebagai berikut: (1) terdapat perbedaan yang signifikan kepercayaan diri siswa dalam belajar pada kelompok eksperimen sebelum dan sesudah diberikan layanan informasi dengan pendekatan contextual teaching and learning, (2) terdapat perbedaan kepercayaan diri siswa dalam belajar pada kelompok kontrol sebelum dan sesudah diberikan layanan informasi tanpa pendekatan contextual teaching and learning, (3) terdapat perbedaan kepercayaan diri siswa dalam belajar kelompok eksperimen yang diberikan layanan informasi dengan pendekatan contextual teaching and learning dengan siswa kelompok kontrol yang diberikan layanan informasi tanpa pendekatan contextual teaching and learning. 
SARAN

1. Bagi siswa setelah mengikuti layanan informasi dengan pendekatan contextual teaching and learning diharapkan dapat menambah wawasan siswa serta dapat meningkatkan kepercayaan diri siswa di dalam belajar.

2. Bagi guru $B K /$ Konselor sebagai bahan pertimbangan dalam memilih layanan yang tepat untuk meningkatkan kepercayaan diri siswa di dalam belajar.

3. Bagi Sekolah sebagai salah satu pedoman dalam menyusun program sekolah berikutnya khususnya dalam mengatasi masalah rendahnya kepercayaan diri siswa di dalam belajar.

4. Bagi Musyawarah Guru Bimbingan dan Konseling (MGBK) sebagai bahan masukan dalam penyusunan program pelayanan Bimbingan dan Konseling, maupun sebagai solusi dari permasalahan salah satunya berkenaan dengan kepercayaan diri siswa dalam belajar.

5. Bagi Dinas Pendidikan khususnya Kota Padang untuk dapat memberikan dukungan dan turut berpartisipasi dalam meningkatkan kepercayaan diri siswa dalam belajar, salah satu cara yang dapat dilakukan adalah selalu memberikan penyediaan sarana pendidikan yang baik.

6. Bagi Program Studi S2 Bimbingan dan Konseling Fakultas Ilmu Pendidikan
Universitas Negeri Padang dapat digunakan dalam rangka mempersiapkan guru BK/Konselor agar memiliki wawasan, pengetahuan, dan keterampilan dalam mengatasi rendahnya kepercayaan diri siswa di dalam belajar.

\section{DAFTAR RUJUKAN}

Ahmad, R. 2013. Dasar-dasar Bimbingan dan Konseling. Padang: UNP Press.

Daryanto dan Rahardjo, M. 2012. Model Pembelajaran Inovatif. Yogyakarta: Gava Media.

Fatimah, E. 2006. Psikologi Perkembangan (Perkembangan Peserta Didik). Bandung: Pustaka Setia.

Hakim, T. 2002. Mengatasi Rasa tidak Percaya Diri. Jakarta: Puspa Swara

Prayitno dan Amti, E. 2004. Dasar-dasar $B K$. Jakarta: Rineka Cipta.

Prayitno. 2012. Seri Layanan Konseling. Padang: UNP Press.

Prayitno. 2013. Konseling Integritas. Padang: UNP Press.

Rakhmat, J. 2010. Psikologi Komunikasi. Bandung: Remaja Rosdakarya.

Surya, H. 2007. Percaya Diri itu Penting. Jakarta: Elek Media Komputindo.

Walgito, B. 2004. Bimbingan dan Konseling (Studi dan Karir). Yogyakarta: Andi Offset. 